\title{
Evaluating the Service Quality of Mobile Health Versus Clinic Based Intervention in Hearing Healthcare. A Comparative Study
}

\author{
https://doi.org/10.3991/ijim.v15i10.21725 \\ Florian Ross $\left({ }^{\bowtie}\right)$, Atilla Wohllebe \\ MATE Hungarian University of Agriculture and Life Sciences - Kaposvár Campus, \\ Kaposvár, Hungary \\ ross.florian@gmx.de
}

\begin{abstract}
Hearing Healthcare is in midst of a paradigm shift and the use of mobile health technologies plays therefore a major role. Through the Bluetooth connectivity between the hearing aids and the smartphone with an accompanying app, the HCP can remotely access hearing aid settings during an online video session. In this study, 30 subjects were divided into a tele-audiology intervention and a clinic-based control group and followed up after an initial fitting for four weeks. At the beginning, structured interviews were used to determine the expectations on the service quality of a Hearing Aid Company, and these were compared with the actual perceived performances at the end of the study using the SERVQUAL model. Various advantages and disadvantages of both forms of intervention were identified. It could be concluded that a combination of both variants ensures the greatest possible perception of service quality.
\end{abstract}

Keywords-Hearing Healthcare, Mobile Health, Service Quality, TeleMedicine

\section{$1 \quad$ Introduction}

It is estimated that about $30 \%$ of men and $20 \%$ of women have a hearing loss $>30 \mathrm{~dB}$ by age 70 . At 80 , this figure rises up to $55 \%$ for men and $45 \%$ for women [1]. Poor hearing and understanding leads to a decrease in quality of life due to a reduction in social activities, the feeling of being excluded, and an increase in symptoms of depression [2]. In most cases, the provision of hearing aids by a Hearing Care Professional (HCP) is the only way to compensate the hearing loss [3]. These devices have undergone an impressive development. Starting with an ear trumpet, which amplified the acoustic signals in the simplest way, to today's high-tech system that automatically detects the most diverse hearing situations and adjusts the hearing aid setting accordingly [4]. The current generation of hearing aids is already equipped with Bluetooth [5], which enables the connection to a smartphone. Using the associated apps, the patient then has access in a limited way to the hearing aid's settings. Over the mentioned applications, HCPs can invite the patients to a tele-audiology online video 
session and can change the hearing aid settings remotely from the clinic [6]. The significance of hearing aid accompanying smartphone apps increased in Hearing Healthcare in the last years [7] and the rapidly advancing digital transformation poses new challenges for medicine in general [8]. To take these challenges into account, the quantity of the small programs is also increasing in the field of telemedicine [9], [10]. The same trend can be seen in other sectors outside of medicine, such as tourism, education and retail. Here, too, companies are increasingly turning to mobile smartphone apps [11]-[13]. On the one hand, socio-economic reasons are central to user acceptance and the associated actual use [14]; on the other hand, perceived added value, such as time or money savings, play an important role [15], [16] which should be noticed by app developers [17].

Several publications already addressed the audiological context of using smartphone-based tele-audiology [7]. The purpose of this article is to examine in more detail the perceived service quality and patient's satisfaction when using the tele - audiology subset of hearing aid accompanying smartphone apps. An exploratory study was therefore conducted, and the participants divided into a tele-audiology intervention and a clinic-based control group. Follow-up appointments for the intervention group were realized via smartphone based tele-audiology, while the control group received traditional face to face care in the clinic. The results were collected and compared within the SERVQUAL method.

This paper aims to complete the research in smartphone-based tele-audiology beyond the boundaries of audiological aspects and to encourage HCPs to integrate this form of patient care into the fitting process.

\section{$2 \quad$ Literature Review}

\subsection{Tele-audiological background}

The traditional route to hearing care is through visiting a clinic and fitting of hearing aids by a HCP [3]. Due to the maldistribution of clinics in rural areas and the associated time required for a clinic visit, the need for tele-audiology grew constantly [18]. This type of service started very simple in the early 1960s, using a practitioner in a surgery who adjusted hearing aids under the instruction of a HCP he received on the phone or later via video session. The results were from the audiological aspect comparable to traditional care in the clinic [19]. Today, this technology has evolved, and synchronous fitting sessions can be conducted via smartphone apps during an online session [6]. It could be concluded that this method does not have any detrimental effects on hearing aid outcomes and can increase the patient's engagement with the HCP [20]. This issue may be part of a paradigm shift in Hearing Healthcare, away from the traditional clinic centric model to a more flexible one, where the patient is more empowered in the whole fitting process and the use of mobile apps plays therefor a major role [21]. Tognola et. al. described this paradigm shift as a silent and disrupting revolution in hearing healthcare due to the increasing use of $\mathrm{e}$ - health methods and technologies, in particular mobile smartphone applications [22]. 
A study among 258 audiologists in the USA found out that HCPs are generally open to the use of smartphone-based tele-audiology as it can generate benefits for the clinic as well as for patients [23]. A similar willingness regarding the use of teleaudiological practices could be confirmed in several older publications in the context of traditional non-smartphone based tele-audiology [24], [25].

\subsection{Mobile health technologies - user satisfaction and service quality}

In the intersection of medical informatics, public health and business, e-health is an emerging field, referring to health services and information delivered or enhanced through the internet and related technologies [26]. M-health can be defined as a subset of this, using mobile devices to deliver health services to the customers [27]. The use of this technologies is increasing, due to benefits like the promotion of preventive behaviors and health monitoring, enhanced patient-doctor engagement, improved service quality and patient centered care [28]. That aspects have an impact in patient satisfaction, which is one of the most important measures in healthcare provision [29]. Several studies have been conducted to evaluate user satisfaction from m-health, which demonstrated high satisfaction rates among patients [30]-[32]. However, it must be mentioned limiting that in these studies the m-health technologies were used as an adjunct to conventional clinic treatment and not as the sole medical intervention [33]. In a direct comparison between mobile health and clinic-based intervention for Serious Mental Illness, it was found that both variants were able to achieve good results in treatment. The level of satisfaction was comparable in both groups and the mhealth treatment showed superior level of patient engagement [34].

In terms of user satisfaction, the application of mobile health technologies, especially in the field of telemedicine, must also pay attention to the practitioner side. Various studies from 2020 during the Covid-19 pandemic could confirm that there is a high degree of user satisfaction among Healthcare workers as well [35]-[37].

Especially with regard to the patient side, service quality plays a decisive role to achieve a high degree of satisfaction [38]. It can be defined as the difference between the actual consumers' perceptions of services and their expectations placed on them [39]. For companies it is significant to measure those expectations because it leads to an increase of the overall long-term quality [40]. Especially in healthcare, where Hearing Healthcare is a part of it, the quality is highly important due to the aspect that the service affects directly the well-being and expectation of life [41]. In literature, several models with the purpose to measure the service quality can be found. In this study, the SERVQUAL model was applied, as it considers the dimensions tangibility, reliability, responsiveness, assurance and empathy. It measures the differences between expectations and perceptions along every dimension with totally 22 items using a gap analysis [39]. The model is based on existing and tested psychological processes and was initially designed to measure customer perceptions of service quality in retail businesses [42], to which the distribution of hearing aids belong as well [43]. 


\section{Materials and Methods}

\subsection{Research methodology}

The hearing aids were fitted to all participants in both groups under laboratory conditions at a neutral location by the study director. Based on the hearing loss, the devices were fitted to the target gain and the handling was explained in detail. The hearing aids of the intervention group were connected to the prepared smartphones and the subjects were instructed in the navigation of the app. Further, four follow-up appointments were arranged at intervals of one week each for subjects of both groups. The tele-audiology intervention group was followed up via online sessions from the clinic, while the control group visited the clinic in person. The supervising HCP was always the same in both groups. After the last session, an appointment was made with the study director again at a neutral location to finalize the study.

In order to measure the service quality, a 22-item questionnaire was developed according to the SERVQUAL method [42]. The subjects were interviewed two times, first at the beginning of the study to inquire the expectations on the service quality of a Hearing Care company and again at the end of the study to determine the actual perceived performance. To assess the participant's level of agreement with the statements regarding expectations and perceptions, a 7-point Likert scale, from $1=$ strongly disagree to $7=$ strongly agree, was applied to all 22 items. The individual scores between the expected and actual perceived service were compared and the difference was determined. These gaps were finally checked statistically to make the results valid.

\subsection{Participants}

The study was conducted with 30 participants (17 male, 13 female). They were divided into a tele-audiology intervention and a clinic-Based control group of $15 \mathrm{sub}$ jects each. The inclusion criteria were as follows: $\leq 75$ years, average air conduction hearing loss in the frequencies $0.5,1,2$ and $4 \mathrm{kHZ}$ between $25 \mathrm{~dB}$ and $75 \mathrm{~dB}$ across both ears. Experience with hearing aids $\geq 2$ years. In addition, care was taken in the selection of participants to ensure that they were familiar with smartphone use. The median age was 64 in the intervention and 63 in the control group.

\subsection{Hearing aids and smartphone app}

The hearing aid model used in this study was the Signia, Pure Charge \& Go 7X, a RIC (Receiver in Channel) hearing aid which counts to the premium segment of hearing aid technologies. It is equipped with $2.4 \mathrm{GHz}$ Bluetooth technology that enables the communication with the patient's smartphone. The hearing aid accompanying smartphone App, Signia App, was used. With this app, an online video session can be realized between the patient and the HCP. This sub-section of the app named Telecare, allows the professional a complete access to the hearing aid's settings and fit- 
ting values, without any bigger limitations compared to traditional care in the clinic. To ensure a consistent study design, all subjects of the intervention group were provided with Apple iPhone 8 smartphones.

\section{$4 \quad$ Results}

In the first step, the questionnaire setup was validated using the Cronbach Alpha Test. In a pretest, the scale reliability of alpha $=0.79$ for the expectations and alpha $=$ 0.82 for the perceptions could be determined. Accordingly, the reliability results from this test were supported.

Table 1 provides an overview about the items used in this study, as well as the means of expectations and perceptions of the tele-audiology intervention and the clinic-based control group. T-tests were used to confirm that the gaps are statistically significant. All results were significant with $\mathrm{p}<.05$. Further, the results were calculated for every dimension with the aim to improve the comparability. The means of expectations were high in both groups and ranged in the tele-audiology intervention group from 6.8 (Item: The HCP has a high level of competence and expertise) to 5.27 (Item: The interests of the patients are the main focus for the HCP). The range in the clinic-based control group was from 6.73 (Item: The HCP has a high level of competence and expertise) to 5.2 (Item: The HCP is visually appealing).

In the tele-audiology intervention group, the mean scores of the perceived service quality reached from 6.27 (Item: Services are executed in the promised time) to 4.47 (Item: The fitting environment is visually appealing) and in the clinic-based control group from 5.94 (Item: The HCP conveys a sense of seriousness during the fitting process) to 4.6 (Item: The services are convenient for disabled patients). The biggest gaps between expectations and perceptions could be observed for the intervention group in the dimension tangibility and for the control group in the dimension empathy. 
Table 1. Service Quality Scores

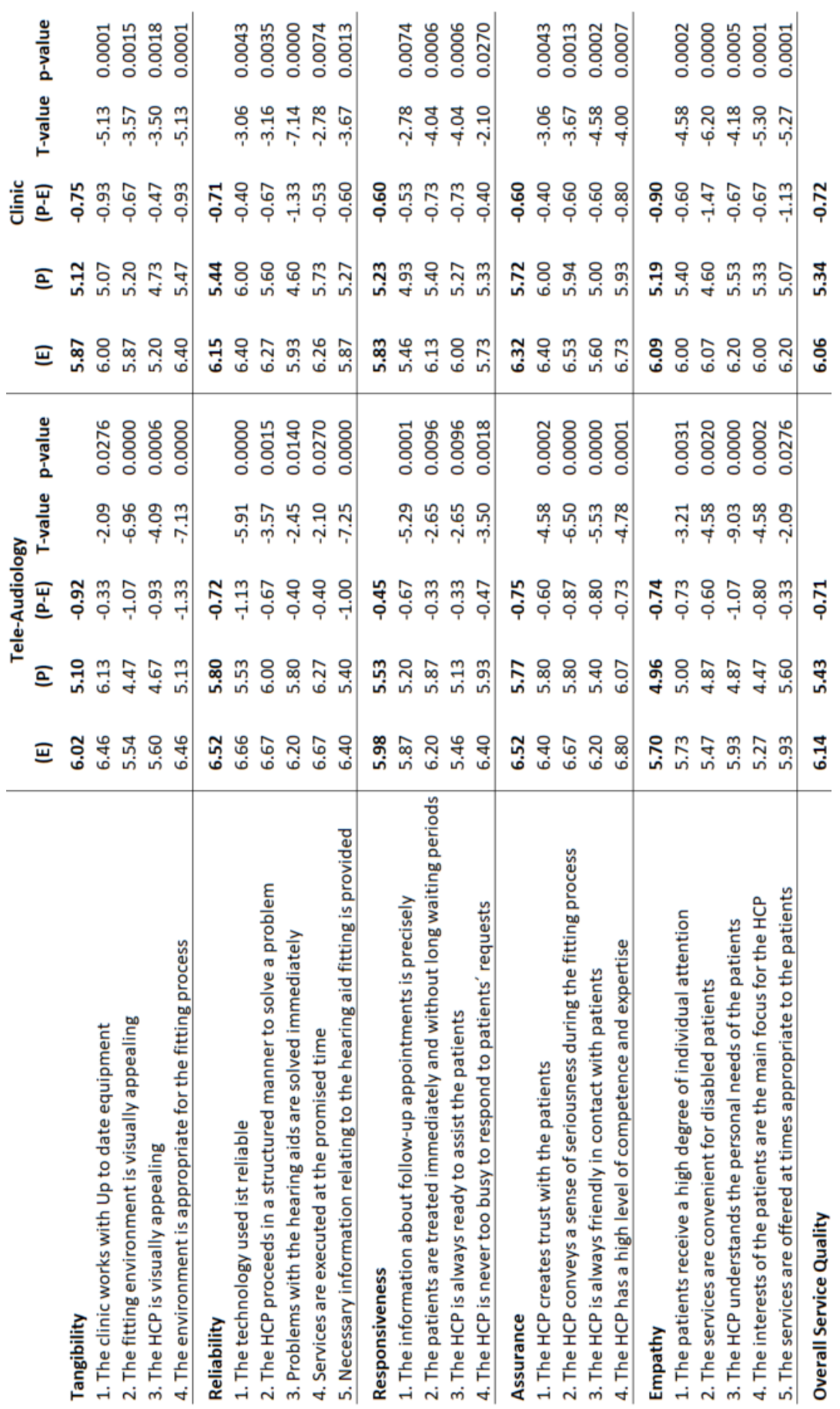


The several gaps between expectations and perceptions can be taken from figure 1 along all dimensions.

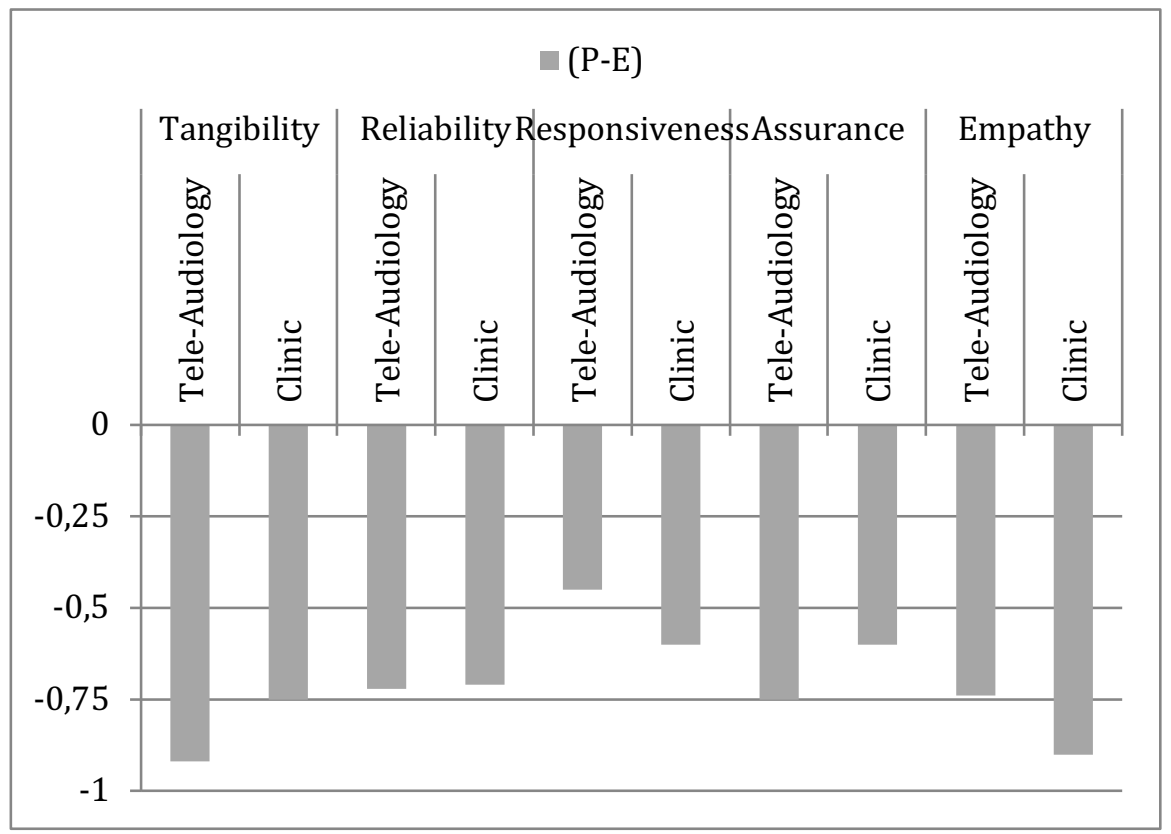

Fig. 1. Gaps along all dimensions

\section{Discussion}

The study assessed the perceived service quality of the two intervention forms on a stand-alone basis. Care was taken in the setup to ensure that there was a clear delineation between the two forms and that they were not mixed. Analyzing the average gaps of the two variants across all 22 items, it is noteworthy that the overall service quality differs only slightly. Accordingly, the overall expectations and perceptions were also on a similar level. However, a closer look at the several dimensions, as well as the several items, reveals various significant differences that play a major role in interpreting the results.

In the area of Tangibility it may be assumed that the advantages in terms of service quality are in favor of the clinic-based control group. This can also be determined in most items. For example, due to an appealing clinic design and the positive appearance of the HCP, the visual aspects were rated better compared to the tele-audiology intervention group. Very remarkable was the aspect that through the smartphone based tele-audiological intervention, the equipment used was perceived as more modern. Here, the conclusion can be drawn that through this form of treatment, the hearing care company is considered as more up to date than others who do not use this variant. 
In the dimension of Reliability, too, the differences between the two variants only become apparent when the individual items are analyzed in more detail. For the technique reliability, a smaller gap was found for the clinic-based control group. It should be mentioned limiting here that three subjects of the tele-audiology group had connectivity problems between the smartphone and the hearing aids due to Bluetooth issues which made scheduled online follow ups not feasible. Accordingly, this point was rated lower. Regarding the necessary information related to the fitting process, an advantage for the clinical group could be determined, which may be because of more extensive communication during face-to-face appointments. On the other side, the Tele-audiology variant had a clear advantage in the area of speed of problem solving, as well as in the punctual implementation of planned service. These conditions can also be observed in the dimension of Responsiveness. The patients were treated without longer waiting periods, the HCP was always ready to assist and never too busy to respond to patients' requests. The explanation here is simple. It just took less time to respond over the app or to perform a short follow up in between whenever it was necessary. Compared to the Clinic Based control group, the HCP was much more flexible, and the patients received a fast and uncomplicated service. In terms of information about follow-up appointments, smaller gaps were determined for the faceto-face variant. Here again and based on the interviews it can be assumed that the communication is more extensive.

In the dimension of Assurance, a higher degree of the perceived service quality was found in interpersonal aspects such as trust, seriousness, and friendliness in the clinic-based control group. In contrast, however, it must be emphasized that the perception of the HCP's competence and expertise tended to be more positive in the intervention group. This aspect coincides with the result from the Tangibility dimension that the equipment of the intervention group was evaluated as more modern. Thus, the study shows that the use of modern tele-audiology technologies has a positive influence on professional and technical conditions. In the dimension of Empathy, the items relating to the level of individual attention, understanding of the patient's personal needs, and attention to the patient's interests were rated better in the clinic-based control group. Lower gaps and thus a higher level of perceived service quality was determined here. These values confirm the results from the previous dimension. It can therefore be concluded that there are advantages at the communication and interpersonal level in the area of face-to-face communication.

\section{Conclusion}

The study demonstrated very clearly the strengths and weaknesses of both intervention forms in the area of perceived service quality. Across dimensions, it can be stated that the intervention via smartphone-based tele-audiology has clear advantages in the area of speed in the implementation of processes compared to the traditional clinic variant. In addition it has a positive impact on professional competence, as the expertise of the HCP is perceived to be higher and the equipment used more modern. On the other hand, a higher level of perceived service quality was found in the face - 
to - face intervention in other aspects. There were clear advantages in the interpersonal area as well as in the provision of information, indicating more extensive communication compared to the tele-audiology variant.

It can therefore be concluded that the highest possible service quality is achieved when the two forms are combined in a meaningful way. The personal appointments in the clinic are the foundation of the patient relationship in the hearing aid fitting process, which can be noticeably optimized by the digital accompaniment of smartphonebased tele-audiology. The demand for this service will certainly increase significantly in the coming years due to demographic changes. Further research is therefore indicated to investigate the expectations of future patient generations on the application of mobile health technologies in Hearing Healthcare as well as the requirements from the practitioner side.

\section{$7 \quad$ References}

[1] T. N. Roth, D. Hanebuth, and R. Probst, "Prevalence of age-related hearing loss in Europe: a review," Eur. Arch. Otorhinolaryngol., vol. 268, no. 8, pp. 1101-1107, Aug. 2011, https://doi.org/10.1007/s00405-011-1597-8

[2] S. Arlinger, "Negative consequences of uncorrected hearing loss-a review," Int. J. Audiol., vol. 42, no. sup2, pp. 17-20, Jan. 2003, https://doi.org/10.3109/14992020309074639

[3] ASHA Ad Hoc Committee on Hearing Aid Selection and Fitting, "Guidelines for Hearing Aid Fitting for Adults,” Am. J. Audiol., vol. 7, no. 1, pp. 5-13, Mar. 1998, https://doi. org/10.1044/1059-0889.0701.05

[4] A. Mudry and L. Dodelé, "History of the technological development of air conduction hearing aids,” J. Laryngol. Otol., vol. 114, no. 6, pp. 418-423, 2000, https://doi.org/10. $1258 / 0022215001905977$

[5] J. Florian, "Bluetooth is beginning to make its mark in hearing healthcare," Hear. J., vol. 56, no. 9, p. 28, Sep. 2003, https://doi.org/10.1097/01.hj.0000293433.00432.4e

[6] J. Weaver, "Made-for-iPhone hearing aid has broad appeal, early adopters report," Hear. J., vol. 67, no. 5, pp. 28-30, 2014. https://doi.org/10.1097/01.hj.0000449902.49313.f1

[7] F. Ross, "Hearing Aid Accompanying Smartphone Apps in Hearing Healthcare. A Systematic Review," Appl. Med. Inform., vol. 42, no. 4, pp. 189-199, Nov. 2020.

[8] E. Diez, "Managing A Veterinary Practice: A Guide to Organizational Cul-ture In Veterinary Practice," Int. J. Appl. Res. Bus. Manag., vol. 1, no. 1, pp. 18-26, 2020, https://doi.org/10.51137/ijarbm.2020.1.1.2

[9] F. Luna-Perejon et al., "Evaluation of user satisfaction and usability of a mobile app for smoking cessation," Comput. Methods Programs Biomed., vol. 182, p. 105042, Dec. 2019, https://doi.org/10.1016/j.cmpb.2019.105042

[10] A. Smith, K. de Salas, I. Lewis, and B. Schüz, "Developing smartphone apps for behavioural studies: The AlcoRisk app case study,” J. Biomed. Inform., vol. 72, pp. 108-119, Aug. 2017, https://doi.org/10.1016/j.jbi.2017.07.007

[11] M. Kalogiannakis and S. Papadakis, "Evaluating pre-service kindergarten teachers' intention to adopt and use tablets into teaching practice for natural sci-ences," Int. J. Mob. Learn. Organ., vol. 13, p. 113, Jan. 2019, https://doi.org/10.1504/ijmlo.2019.096479

[12] A. Wohllebe, P. Dirrler, and S. Podruzsik, "Mobile Apps in Retail: Determi-nants of Consumer Acceptance - A Systematic Review," Int. J. Interact. Mob. Technol. IJIM, vol. 14, no. 20, Art. no. 20, Dec. 2020, https://doi.org/10.3991/ijim.v14i20.18273 
[13] F. B. P. Prakasa, M. Radja, and S. Suyoto, "User Experience Based Mobile Application Design for Boat Loaning at Marine Tourism in Indonesia," Int. J. In-teract. Mob. Technol. IJIM, vol. 14, no. 04, Art. no. 04, Mar. 2020. https://doi.org/10.3991/ijim.v14i04.11227

[14] S. Papadakis, N. Zaranis, and M. Kalogiannakis, "Parental involvement and attitudes towards young Greek children's mobile usage,” Int. J. Child-Comput. Interact., vol. 22, p. 100144, Aug. 2019, https://doi.org/10.1016/j.ijcci.2019.100144

[15] M. Rojas-Osorio and A. Alvarez-Risco, "Intention to Use Smartphones among Peruvian University Students," Int. J. Interact. Mob. Technol. IJIM, vol. 13, no. 03, Art. no. 03, Mar. 2019. https://doi.org/10.3991/ijim.v13i03.9356

[16] A. Wohllebe, T. Stoyke, and S. Podruzsik, "Incentives on E-Commerce App Downloads in Medium Apps: A Case Study on the Effects of Coupons and Bonus Points," Int. J. Interact. Mob. Technol. IJIM, vol. 14, no. 19, Art. no. 19, Nov. 2020, https://doi.org/10.3991/ijim. v14i19.16427

[17] S. Papadakis, M. Kalogiannakis, and N. Zaranis, "Educational apps from the Android Google Play for Greek preschoolers: A systematic review," Comput. Educ., vol. 116, pp. 139-160, Jan. 2018, https://doi.org/10.1016/j.compedu.2017.09.007

[18] D. W. Swanepoel et al., "Telehealth in audiology: The need and potential to reach underserved communities,” Int. J. Audiol., vol. 49, no. 3, pp. 195-202, Jan. 2010, https://doi. org/10.3109/14992020903470783

[19] C. Gladden, L. Beck, and D. Chandler, "Tele-audiology: Expanding Access to Hearing Care and Enhancing Patient Connectivity," J. Am. Acad. Audiol., vol. 26, no. 9, pp. 792799, Oct. 2015, https://doi.org/10.3766/jaaa.14107

[20] E. Convery, G. Keidser, M. McLelland, and J. Groth, "A Smartphone App to Facilitate Remote Patient-Provider Communication in Hearing Health Care: Usa-bility and Effect on Hearing Aid Outcomes," Telemed. E-Health, 2019. https://doi.org/10.1089/tmj.2019.0109

[21] A. Paglialonga, G. Tognola, and F. Pinciroli, “Apps for Hearing Healthcare," Stud. Health Technol. Inform., pp. 666-668, 2015, https://doi.org/10.3233/978-1-61499-512-8-666.

[22] G. Tognola, A. Paglialonga, E. Chiaramello, and F. Pinciroli, "eHealth for hearing-New views and apps practicalities," Eur. J. Biomed. Inform., vol. 11, no. 3, 2015. https://doi. org/10.24105/ejbi.2015.11.3.7

[23] S. H. Kimball, G. Singh, A. B. John, and L. M. Jenstad, "Implications and at-titudes of audiologists towards smartphone integration in hearing healthcare," Hear. Res., vol. 369, pp. 15-23, 2018. https://doi.org/10.1016/j.heares.2018.06.011

[24] R. H. Eikelboom and M. D. Atlas, "Attitude to telemedicine, and willingness to use it, in audiology patients," J. Telemed. Telecare, vol. 11, no. 2_suppl, pp. 22-25, Dec. 2005, https://doi.org/10.1258/135763305775124920

[25] G. Singh, M. K. Pichora-Fuller, M. Malkowski, M. Boretzki, and S. Launer, "A survey of the attitudes of practitioners toward teleaudiology," Int. J. Audiol., vol. 53, no. 12, pp. 850-860, 2014. https://doi.org/10.3109/14992027.2014.921736

[26] G. Eysenbach, "What is e-health?” J. Med. Internet Res., vol. 3, no. 2, p. e20, 2001, https://doi.org/10.2196/jmir.3.2.e20

[27] P. N. Mechael, "The Case for mHealth in Developing Countries," Innov. Technol. Gov. Glob., vol. 4, no. 1, pp. 103-118, Jan. 2009, https://doi.org/10.1162/itgg.2009.4.1.103

[28] A. Paglialonga, A. Mastropietro, E. Scalco, and G. Rizzo, "The mHealth," in m_Health Current and Future Applications, G. Andreoni, P. Perego, and E. Fru-mento, Eds. Cham: Springer International Publishing, 2019, pp. 5-17.

[29] R. Fitzpatrick, "Surveys of patients satisfaction: I--Important general considerations.," BMJ, vol. 302, no. 6781, pp. 887-889, Apr. 1991. https://doi.org/10.1136/bmj.302.6781. $\underline{887}$ 
[30] Y. M. Chae, J. Heon Lee, S. Hee Ho, H. Ja Kim, K. Hong Jun, and J. Uk Won, "Patient satisfaction with telemedicine in home health services for the elderly.," Int. J. Med. Inf., vol. 61, no. 2-3, pp. 167-173, May 2001, https://doi.org/10.1016/s1386-5056(01)00139-3

[31] B. Aljasir and M. S. Alghamdi, "Patient satisfaction with mobile clinic ser-vices in a remote rural area of Saudi Arabia,” EMHJ - East. Mediterr. Health J. 1610 1085-1090 2010, 2010. https://doi.org/10.26719/2010.16.10.1085

[32] K. Patrick, W. G. Griswold, F. Raab, and S. S. Intille, "Health and the mobile phone.," Am. J. Prev. Med., vol. 35, no. 2, pp. 177-181, Jun. 2008, https://doi.org/10.1016 /j.amepre.2008.05.001

[33] H. Lee et al., "Patient Satisfaction with Mobile Health (mHealth) Applica-tion for Exercise Intervention in Breast Cancer Survivors," J. Med. Syst., vol. 42, no. 12, p. 254, Nov. 2018, https://doi.org/10.1007/s10916-018-1096-1

[34] D. Ben-Zeev et al., "Mobile Health (mHealth) Versus Clinic-Based Group Intervention for People with Serious Mental Illness: A Randomized Controlled Tri-al,” Psychiatr. Serv., vol. 69, no. 9, pp. 978-985, May 2018, https://doi.org/10.1176/appi.ps.201800063

[35] A. Dobrusin et al., "Gastroenterologists and Patients Report High Satisfac-tion Rates with Telehealth Services During the Novel Coronavirus 2019 Pandem-ic," Clin. Gastroenterol. Hepatol., vol. 18, no. 11, pp. 2393-2397.e2, Oct. 2020, https://doi.org/10.1016/j.cgh.2020. $\underline{07.014}$

[36] E. Layfield et al., "Telemedicine for head and neck ambulatory visits during COVID-19: Evaluating usability and patient satisfaction," Head Neck, vol. 42, no. 7, pp. 1681-1689, 2020, https://doi.org/10.1002/hed.26285. https://doi.org/10.22541/au.158921760.08703602

[37] M. Fieux, S. Duret, N. Bawazeer, L. Denoix, S. Zaouche, and S. Tringali, "Telemedicine for ENT: Effect on quality of care during Covid-19 pandemic," Eur. Ann. Otorhinolaryngol. Head Neck Dis., vol. 137, no. 4, pp. 257-261, Sep. 2020, https://doi.org/10.1016/j. anorl.2020.06.014

[38] H.-H. (Sunny) Hu, J. Kandampully, and T. D. Juwaheer, "Relationships and impacts of service quality, perceived value, customer satisfaction, and image: an empirical study," Serv. Ind. J., vol. 29, no. 2, pp. 111-125, Feb. 2009, https://doi.org/10.1080/0264206080 2292932

[39] A. Parasuraman, V. A. Zeithaml, and L. L. Berry, "A Conceptual Model of Service Quality and Its Implications for Future Research,” J. Mark., vol. 49, no. 4, pp. 41-50, Sep. 1985, https://doi.org/10.1177/002224298504900403

[40] C. Grönroos, Service Management and Marketing - Customer Management in Service Competition. 2007.

[41] M. Sabahi-Bidgoli, S. G. A. Mousavi, A. Kebriaei, S. H. Seyyedi, S. Shahri, and M. Atharizadeh, "The quality of hospital services in Kashan educational hos-pitals during 2008-9: the patients' viewpoint," KAUMS J. FEYZ, vol. 15, no. 2, pp. 146-152, Jun. 2011.

[42] A. Parasuraman, V. Zeithaml, and L. Berry, "SERVQUAL: A Multiple-Item Scale For Measuring Consumer Perceptions of Service Quality,” J. Retail., vol. 64, no. 1, 1988, Accessed: Jan. 11, 2021. [Online]. Available: https://search.proquest.com/docview/22860 9374?pq-origsite $=$ gscholar \& fromopenview $=$ true

[43] F. Ross, "A Perspective on the Application of Kapferer's Brand Identity Prism in the Branding Process of Hearing Aid Retail Companies," J. Manag. Mark. Rev., vol. 5, no. 3, pp. 141-146, Sep. 2020, https://doi.org/10.35609/jmmr.2020.5.3(2) 


\section{Authors}

Florian Ross is currently working on his $\mathrm{PhD}$ at the Doctoral School in Management and Organizational Sciences, MATE Hungarian University of Agriculture and Life Sciences - Kaposvár Campus, Hungary. His research focuses on hearing-aids, mobile health and retail. Ross currently lives in Regensburg, Germany, where he runs several hearing aids shops.

Atilla Wohllebe works in retail and e-commerce. He helps companies to meet the challenges of digitization both strategically and technologically. He holds a M. Sc. in E-Commerce from Wedel University of Applied Sciences, Germany, and is currently a Ph. D. student at MATE Hungarian University of Agricultural and Life Sciences Kaposvár Campus, Hungary. His research topics include mobile apps \& digital marketing, e-commerce \& retail, and agile working methods.

Article submitted 2021-02-03. Resubmitted 2021-03-03. Final acceptance 2021-03-04. Final version published as submitted by the authors. 